\title{
The RCK2 Domain Uses a Coordination Site Present in Kir Channels to Confer Sodium Sensitivity to Slo2.2 Channels
}

\author{
Zhe Zhang, ${ }^{1}$ Avia Rosenhouse-Dantsker, ${ }^{2}$ Qiong-Yao Tang, ${ }^{1}$ Sergei Noskov, ${ }^{3}$ and Diomedes E. Logothetis ${ }^{1}$ \\ ${ }^{1}$ Department of Physiology and Biophysics, Virginia Commonwealth University, School of Medicine, Richmond, Virginia 23298, ${ }^{2}$ Department of Medicine, \\ University of Illinois at Chicago, Chicago, Illinois 60612, and 'Institute of Biocomplexity and Informatics, Department of Biological Sciences, University of \\ Calgary, Calgary, Alberta T2N 1N4, Canada
}

Slo2 $\mathrm{Na}^{+}$-activated potassium channels are widely expressed in neurons and other cells, such as kidney, heart, and skeletal muscle. Although their important physiological roles continue to be appreciated, molecular determinants responsible for sensing intracellular $\mathrm{Na}^{+}$remain unknown. Here we report identification of an $\mathrm{Na}^{+}$regulatory site, similar to an $\mathrm{Na}^{+}$coordination motif described in Kir channels, localized in the RCK2 domain of Slo2.2 channels. Molecular simulations of the homologymodeled Slo2.2 RCK2 domain provided structural insights into the organization of this $\mathrm{Na}^{+}$coordination site. Furthermore, free energy calculations reproduced the experimentally derived monovalent cation selectivity. Our results suggest that Slo2.2 and Kir channels share a similar mechanism to coordinate $\mathrm{Na}^{+}$. The localization of an $\mathrm{Na}^{+}$sensor within the RCK2 domain of Slo2.2 further supports the role of RCK (regulators of conductance of $\mathrm{K}^{+}$) domains of Slo channels in coupling ion sensing to channel gating.

\section{Introduction}

The $\mathrm{Na}^{+}$-activated potassium channel $\left(\mathrm{K}_{\mathrm{Na}}\right)$ currents were first recorded in guinea pig ventricular myocytes (Kameyama et al., 1984). The open probability of these highly selective $\mathrm{K}^{+}$channels was found to be steeply dependent on the $\mathrm{Na}^{+}$concentration (Kameyama et al., 1984). The $\mathrm{K}_{\mathrm{Na}}$ channel Slo2.2 [or Slack (for

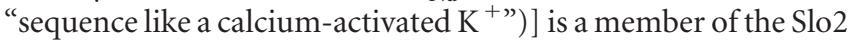
gene family (Yuan et al., 2003). There are two N-terminal splice variants of the Slack mRNA, a shorter Slack-A and a longer Slack-B. The rSlack-B gene encodes a 1237 aa protein, which can form homomeric channels but can also coassemble with another homologous protein named Slick [for "sequence like an intermediate conductance K channel" (Slo2.1)] to form heteromeric channels (Bhattacharjee et al., 2003; Brown et al., 2008; Chen et al., 2009). The full-length rat Slick gene encodes a protein of 1142 aa that shares $74 \%$ sequence identity to the rat Slack protein. Sodium-activated $\mathrm{K}^{+}$channels $\left(\mathrm{K}_{\mathrm{Na}}\right.$ channels) are members of a family of high-conductance potassium ion channels. Their amino acid sequence contains six putative membrane-spanning

\footnotetext{
Received Jan. 30, 2010; revised April 6, 2010; accepted April 15, 2010.

Z.Z. was supported by American Heart Association Grant 09SDG2290002. D.E.L. was supported by National Institutes of Health Grants HL059949-11 and HL090882-01. S.N. was supported by Canadian Institutes of Health Research (CIHR) Operating Grant MOP-186232. S.N. is a CIHR New Investigator and an Alberta Heritage Foundation for Medical Research Scholar. The computational support for this work was provided by the West-Grid Canada through resource allocation award to S.N. S.N. acknowledges useful discussions with Benoit Roux and Toby Allen on the ion binding computations. We are thankful to Heikki Vaananen and Sophia Gruszecki for Xenopus 0ocyte isolation and to the Logothetis laboratory members for insightful discussions and comments throughout this project. We are grateful to Dr. Kaczmarek (Department of Pharmacology, Yale University, New Haven, (T) for providing us with the Slack-B cDNA.

Correspondence should be addressed to Diomedes E. Logothetis, Department of Physiology and Biophysics, Virginia Commonwealth University School of Medicine, Richmond, VA 23298-0551. E-mail: delogothetis@vcu.edu. DOI:10.1523/JNEUROSCI.0525-10.2010

Copyright $\odot 2010$ the authors $\quad 0270-6474 / 10 / 307554-09 \$ 15.00 / 0$
}

domains, a P-region between predicted transmembrane domains 5 and 6, and an extensive C-terminal region. The C-terminal region of both Slick and Slack is predicted to encode two RCK (regulators of conductance of $\mathrm{K}^{+}$) domains, similar to the Slo1 gene that encodes the large-conductance calcium-activated potassium channel (Jiang et al., 2002a,b). Thus far, the molecular determinants of the sodium regulatory site(s) of the Slack channel remain unknown.

Sodium-activated potassium channels are widely expressed in the CNS and in heart (Egan et al., 1992; Bhattacharjee et al., 2002). $\mathrm{K}_{\mathrm{Na}}$ channels may play an important role in synaptic transmission (Nanou and El Manira, 2007; Nanou et al., 2008), in the modulation of the action-potential waveform (Yang et al., 2007; Gao et al., 2008), and in the responses of excitable cells to hypoxia and ischemia (Dryer, 1994).

Native G-protein-sensitive inwardly rectifying $\mathrm{K}^{+}$(GIRK) $\left(\mathrm{K}_{\mathrm{Ach}}\right.$ or Kir3) channels are also activated by $\mathrm{Na}^{+}$(Sui et al., 1996). $\mathrm{Na}^{+}$activation of Kir3 channels is limited to the neuronal Kir3.2 (GIRK2) and the cardiac Kir3.4 (GIRK4) subunits. Chimeras between Kir3.1 and Kir3.2 or Kir3.4 identified a critical Asp residue (GIRK2-D226 and GIRK4-D223) as a sodium regulatory site in the Kir3.2 channel (Ho and Murrell-Lagnado, 1999a; Zhang et al., 1999). The reverse equivalent mutation N217D in the Kir3.1 channel and N216D in the Kir2.1 (IRK1) channel conferred sodium sensitivity to these channels (Ho and Murrell-Lagnado, 1999b; Zhang et al., 1999). Molecular dynamics (MD) simulations using the structure of Kir3.1 combined with experimental tests revealed that the Asp coordinates the $\mathrm{Na}^{+}$ion as part of a loop structure with the aid of a His side chain as well as backbone carbonyls of two other residues (RosenhouseDantsker et al., 2008). Moreover, Kir5.1 that possesses the DXRXXH motif was also shown to be $\mathrm{Na}^{+}$sensitive. 
A

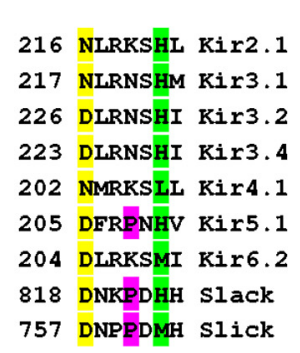

B

SQLLVVILICVTLVVLPLQFEELVY LWMERQKSGGNYSRHRARTEKHVVLC 358 $\$ 6$

VSSLKIDLLMDF LNEFYA HPRLQDYYVVI LCPSEMDVQVRRVLQIPLWSQR 409 VIYLQGSALKDQDLMRAKMDNGEACF ILSSRINEVDRTAADHQTILRAWAVK 460 DEAPNCPLYVQILKPENKE HVKFADHVVCEEECKYAMLALNCICPATSTLI 511 TLLVHTSRGQEGQESPEQWQRMYGRCSGNEVYHIRMGDSKFEREYEGKSET 562 YAAF HAHKKY GVCLIGLKREENKS I LLNP GPRHILAAS DTCFY INI TKEEN 613 SAE IFKQEEKQNRRGLAGQALYEGP SRLPVHSI IASMVAMDLQNTDCRPSQ 664 GGSGGGGGKLTLPTENGSGSRRPSIAPVLELADSSALLPCDILSDQSEDEV 715 TPSDDEGLSVVEYVKGYPPNSPY IGSSPTLGHLLPVKAPECCLRLDKGCKH 766 NSYEDAKAYGEKNKLI IVSAETAGNGLYNF IVP LRAYYRSRRELNP IVLLL 817 DNKPDHHF LEA ICCEPMVYYMEGSVD...
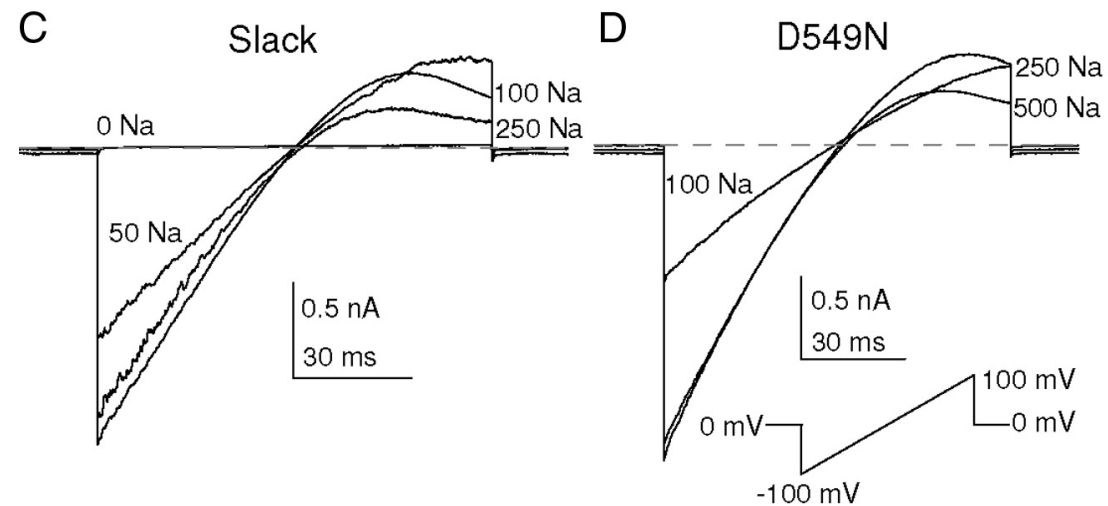

E
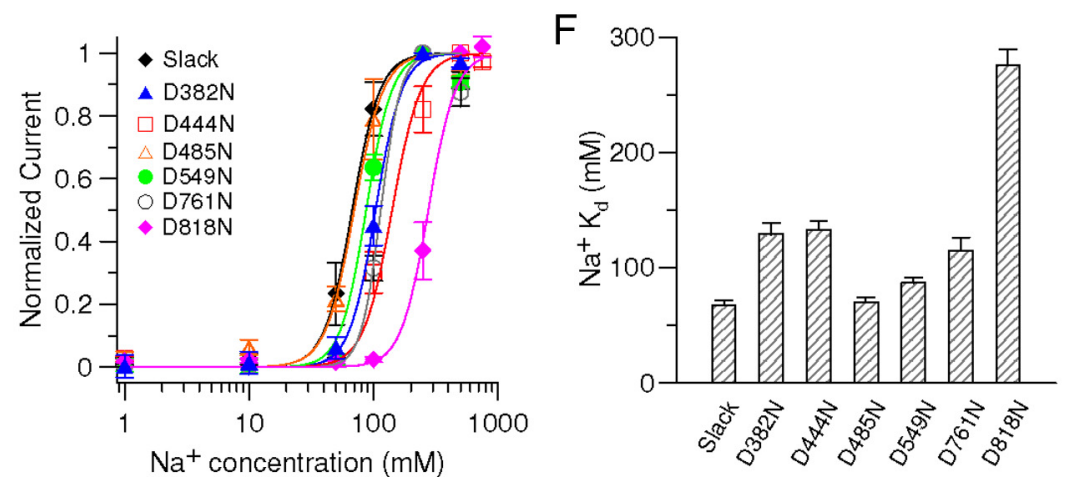

Figure 1. Screening for potential $\mathrm{Na}^{+}$binding site(s) in the $\left(\right.$terminus of the Slack channel. $\boldsymbol{A}$, Comparisons of the $\mathrm{Na}^{+}$ coordination site in Kir channels with the analogous region in Slack and Slick channels. $\boldsymbol{B}$, Based on the $\mathrm{Na}^{+}$coordination site identified in the $C$ terminus of Kir channels, there are six potential similar $\mathrm{Na}^{+}$binding sites in the Slack channel. C, D, Typical current traces recorded in the inside-out patch configuration for Slack and D549N mutants. $\boldsymbol{E}$, Hill equation fitted data of the $\mathrm{Na}^{+}$ dose dependence of wild-type Slack $\left(K_{\mathrm{d}}\right.$ of $\left.67 \pm 3.8 \mathrm{~mm}, n=3.98\right), \mathrm{D} 382 \mathrm{~N}\left(K_{\mathrm{d}}\right.$ of $\left.129 \pm 9.8 \mathrm{~mm}, n=3.9\right), \mathrm{D} 444 \mathrm{~N}\left(K_{\mathrm{d}}\right.$ of $133 \pm$ $4.6 \mathrm{~mm}, n=4$ fixed), D485N ( $K_{\mathrm{d}}$ of $\left.70.3 \pm 4 \mathrm{~mm}, n=3.9\right), \mathrm{D} 549 \mathrm{~N}\left(K_{\mathrm{d}}\right.$ of $\left.87.3 \pm 4.5 \mathrm{~mm}, n=3.93\right), \mathrm{D} 761 \mathrm{~N}\left(K_{\mathrm{d}}\right.$ of $114.8 \pm 11.3$ $\mathrm{mm}, n=3.9)$, and D818N ( $K_{\mathrm{d}}$ of $\left.276 \pm 13.6 \mathrm{~mm}, n=4.0\right)$. $F$, Summary of $K_{\mathrm{d}}$ values for wild-type and all Slack channel mutants tested.

In the present study, we investigated whether the $\mathrm{Na}^{+}$coordination motif found in Kir channels also exists in Slack channels. By screening the Slack-B channel $\mathrm{C}$ terminus with the Kir $\mathrm{Na}^{+} \mathrm{CO}^{-}$ ordination motif sequence, we identified an Asp residue (D818) in the Slack RCK2 domain, the mutation of which dramatically decreased the sodium sensitivity of Slack channels. Additional mutagenesis scanning experiments revealed the His (H823) residue corresponding to the His residue in the Kir motif that also critically contributed to the $\mathrm{Na}^{+}$sensitivity of Slack channels. Molecular simulations and free energy calculations reproduced the experimentally derived monovalent cation selectivity. These results indicate that a conserved $\mathrm{Na}^{+}$coordination site is shared by two different types of $\mathrm{K}^{+}$channels, the $\mathrm{K}_{\mathrm{Na}}$ and Kir channels.

\section{Materials and Methods}

Oocyte isolation and culture. Stage VI Xenopus laevis oocytes were harvested and used for cRNA injection as described previously (RosenhouseDantsker and Logothetis, 2006). Slack and Slick mutant cRNAs were prepared at a concentration of $\sim 1 \mu \mathrm{g} / \mu \mathrm{l}$, and each oocyte was injected with $50 \mathrm{nl}$ of cRNA. Currents were recorded within $3-5 \mathrm{~d}$.

Constructs and mutations. The Slack-B construct (GenBank accession number NP 942057) was a gift from Dr. Kaczmarek (Yale University School of Medicine, New Haven, CT). Slack mutations were made following previously published procedures (Jin et al., 2002).

Electrophysiology. Currents were recorded in the inside-out patch configuration using an EPC 9 amplifier (HEKA) and the Pulse fit program (HEKA). We observed current rundown in $\sim 50 \%$ of excised inside-out patches. All currents were recorded within $30 \mathrm{~s}$ after patch excision to minimize significant rundown (Tamsett et al., 2009), and only patches that did not show rundown were included in the analysis. Patch-clamp recording pipettes were made from borosilicate capillary tubes (PG10150-4; World Precision Instruments) and had resistances of 1-3 M $\Omega$. Gigaohm seals were formed in ND96K-EGTA solution [in mM: $90 \mathrm{KCl}, 20$ HEPES-K, and 50 EGTA-K-02/ 06M (200 mM EGTA and $600 \mathrm{~mm} \mathrm{KOH})$, pH 7.4]. The standard pipette/extracellular solution was also ND96K-EGTA. Different bath solutions (BS) were used. For screening and scanning $\mathrm{Na}^{+}$sensitivity of Slack mutations, BS1 contained the following (in $\mathrm{mm}$ ): $90 \mathrm{KCl}$, 20 HEPES-K, 50 EGTA-K-02/06M, and $0-1000 \mathrm{NaGlu}$. For testing the $\mathrm{Na}^{+}$sensitivity of constructs in the absence of $\mathrm{Cl}^{-}, \mathrm{BS} 2$ contained the following (in $\mathrm{mm}$ ): $90 \mathrm{~mm}$ KGlu, 20 HEPES-K, 50 EGTA-K-02/06M, and 0-1000 $\mathrm{NaGlu}$. For testing sensitivity of constructs to chloride, BS3 contained the following (in $\mathrm{mM}$ ): 90 mM KGlu, 20 HEPES-K, 50 EGTA-K-02/ $06 \mathrm{M}$, and 0-500 choline chloride. Experiments were performed at $22-25^{\circ} \mathrm{C}$. Salts of the compounds mentioned were obtained from Sigma.

Single-channel analysis. Amplitude histograms were measured, idealized, and fitted with a Gaussian function using the software ANA.EXE. The open probability $\left(P_{\mathrm{o}}\right)$ of the channels was calculated using the area under each peak (aj) at each current level $(j)$ in the histogram along with the number of channels $(N)$ as follows:

$$
P_{\mathrm{O}}=\frac{\sum_{j=0}^{N}\left(j^{\star} a j\right)}{n \times \sum_{j=0}^{N} a j} .
$$

Homology modeling. A segment that includes residues 243-321 of the crystallographic structure of the RCK domain from the Escherichia coli $\mathrm{K}^{+}$channel (Protein Data Bank identification number 1id1) (Jiang et al., 2001) was used as the basis for the homology model of the segment of Slo2.2 that includes residues 778-865. The resolution of the crystallographic structure (Protein Data Bank identification number 1id1) was $2.4 \AA$, and the overall similarity (identity, strong and weak similarity) between the sequences of the segments of the RCK domain (residues 
243-321) and Slo2.2 (residues 778-865) was $56 \%$. The basic model was constructed using the protein homology/analogy recognition engine QuickPhyre (Bennett-Lovsey et al., 2008). The homology model was then minimized using the Steepest Descent and the adopted-basis Newton Raphson algorithms as implemented in CHARMM version 32 (Brooks et al., 1983). The final orientation of the side chains in the homology model was obtained after minimization in the presence of sodium.

Molecular modeling. The c35b1 version of the CHARMM program (Brooks et al., 1983) was used to run MD simulations for the Kir3.1N217D cytosolic domain (Protein Data Bank identification number 19NP) and the homology modeled domain of Slo2.2. The $\mathrm{Na}^{+}$ion was introduced at the binding pocket identified in a previous study in Kir channels (Ho and Murrell-Lagnado, 1999a; Rosenhouse-Dantsker et al., 2008). The simulation box contained one protein with one bound $\mathrm{Na}^{+}$solvated by a 100 $\mathrm{mm} \mathrm{NaCl}$ aqueous salt solution, comprising a total of $\sim 48,000$ atoms. The CHARMMGUI interface was used to build all simulation systems (Jo et al., 2009). All simulations were performed at constant pressure ( 1 atmospheric unit) and constant temperature with periodic boundary conditions (Feller et al., 1995). Electrostatic interactions were treated using a particle mesh Ewald algorithm (Essmann et al., 1995). All systems were equilibrated for $1.5 \mathrm{~ns}$ and then subjected to 10 ns production runs. The analysis of root mean square (RMS) fluctuations indicates that structures for wild-type and mutant proteins were stable for the entire simulation time. The SCWRL 4.0 was used to introduce side-chain replacements for construction of mutated amino acid residues (Krivov et al., 2009). To ensure optimal packing for the mutated residue, 2 ns of the reequilibrating MD simulations were performed in the presence of weak harmonic constraints $\left(1 \mathrm{kcal} / \mathrm{mol} / \AA^{2}\right)$ on the backbone before production runs.

Free energy simulations: evaluation of relative ion binding affinities. Free energy perturbation (FEP) simulations to evaluate the absolute free energy of ion uncharging and the relative free energy for site specificity of the sequence $\mathrm{Li}^{+}, \mathrm{Na}^{+}, \mathrm{K}^{+}$were performed using the CHARMM PERT command for the Kir3.1N217D and the Slo2.2 cytosolic domains as well as for the Slo2.2 mutants D818E, D818N, and D818R using a previously developed protocol (Caplan et al., 2008; Noskov and Roux, 2008). A thermodynamic coupling parameter $\lambda$ varying between 0 and 1 was used to alchemically transform $\mathrm{Na}^{+}$into a different ion type $\left(\mathrm{K}^{+}\right.$or $\left.\mathrm{Li}^{+}\right)$, and 11 intermediate windows were used to go from 0 to 1 in increments of 0.1 . A total of 22 windows with $500 \mathrm{ps}$ each were run to obtain converged estimates on the relative free energies. The relative free energies used to characterize the binding site selectivity are as follows:

$$
\Delta \Delta G_{i j}=\Delta G_{i j}^{\text {site }}-\Delta G_{i j}^{\text {bulk }},
$$

where $\Delta G_{i j}^{\text {site }}$ is the difference in free energies of binding to the site between ion $i$ and $j$, and $\Delta G_{i j}^{\text {bulk }}$ is the difference in free energies of hydration between ion $i$ and ion $j$. The positive sign in the relative free energy refers to the preference by the site for ion $i$. The reference values for the absolute free energy of $\mathrm{Li}^{+}, \mathrm{Na}^{+}$, and $\mathrm{K}^{+}$uncharging $\left(G_{\text {elec }}^{\text {bulk }}\right)$ in the bulk water was estimated to be $-113.1,-89.5$, and $-71.9 \mathrm{kcal} / \mathrm{mol}$, respectively. These numbers are reported for simulations with periodic boundary conditions and have to be corrected for the presence of interfacial potential (correction of approximately $-10 \mathrm{kcal} / \mathrm{mol}$ for the model used) to compare directly with experimental measurements. It should be noted that the relative free energies are insensitive to this correction as a result of the cancellation of this term. The reference values for relative free energy differences in the bulk for the model used in our study are $\Delta \Delta G\left(\mathrm{Na}^{+} \rightarrow\right.$ $\left.\mathrm{K}^{+}\right)=18.01 \mathrm{kcal} / \mathrm{mol}$ (FEP simulation) or $\Delta \Delta G\left(\mathrm{Na}^{+} \rightarrow \mathrm{K}^{+}\right)=18.01$ $\mathrm{kcal} / \mathrm{mol}$ (as a difference in absolute free energies) and $\Delta \Delta G\left(\mathrm{Na}^{+} \rightarrow\right.$ $\left.\mathrm{Li}^{+}\right)=-23.4 \mathrm{kcal} / \mathrm{mol}$. All parameters as well as the development protocol have been published previously (Caplan et al., 2008). This approach to absolute and relative free energy computations is rooted in equilibrium thermodynamics of ion solvation but has been proven useful in many studies of ion permeation (Luzhkov and Aqvist, 2001; Noskov et al., 2004; Luzhkov et al., 2006). The weighted histogram analysis method was used to post-process the FEP calculation data (Kumar et al., 1992; Souaille and Roux, 2001).

\section{Results}

\section{A common $\mathrm{Na}^{+}$coordination site used by both $\mathrm{Kir}$} and Slo2.2 channels.

Figure $1 A$ shows a seven residue sequence of the $\mathrm{Kir} \mathrm{Na}^{+}$coordination site that uses the side chains of the amino acid residues Asp and His at positions 1 and 6 separated by 4 aa, one of which is a highly conserved basic residue in position $3(\mathrm{R})$. Three Kir channels (Kir3.2, Kir3.4, and Kir5.1) that possess the motif DXRXXH were shown to be $\mathrm{Na}^{+}$sensitive, whereas others (Kir2.1 and Kir3.1) could be made $\mathrm{Na}^{+}$sensitive by engineering the motif through mutagenesis (Zhang et al., 1999; RosenhouseDantsker et al., 2008). Six potential sites in the $\mathrm{C}$ terminus of the Slack channel were similar to the Kir $\mathrm{Na}^{+}$coordination motif, including an aspartate and a histidine separated by four to five residues, with a positively charged residue $(\mathrm{R} / \mathrm{K})$ between these two residues (Fig. $1 B$ ). In view of the flexibility of the CD loop that includes the sodium-binding motif in Kir channels, the pos- 

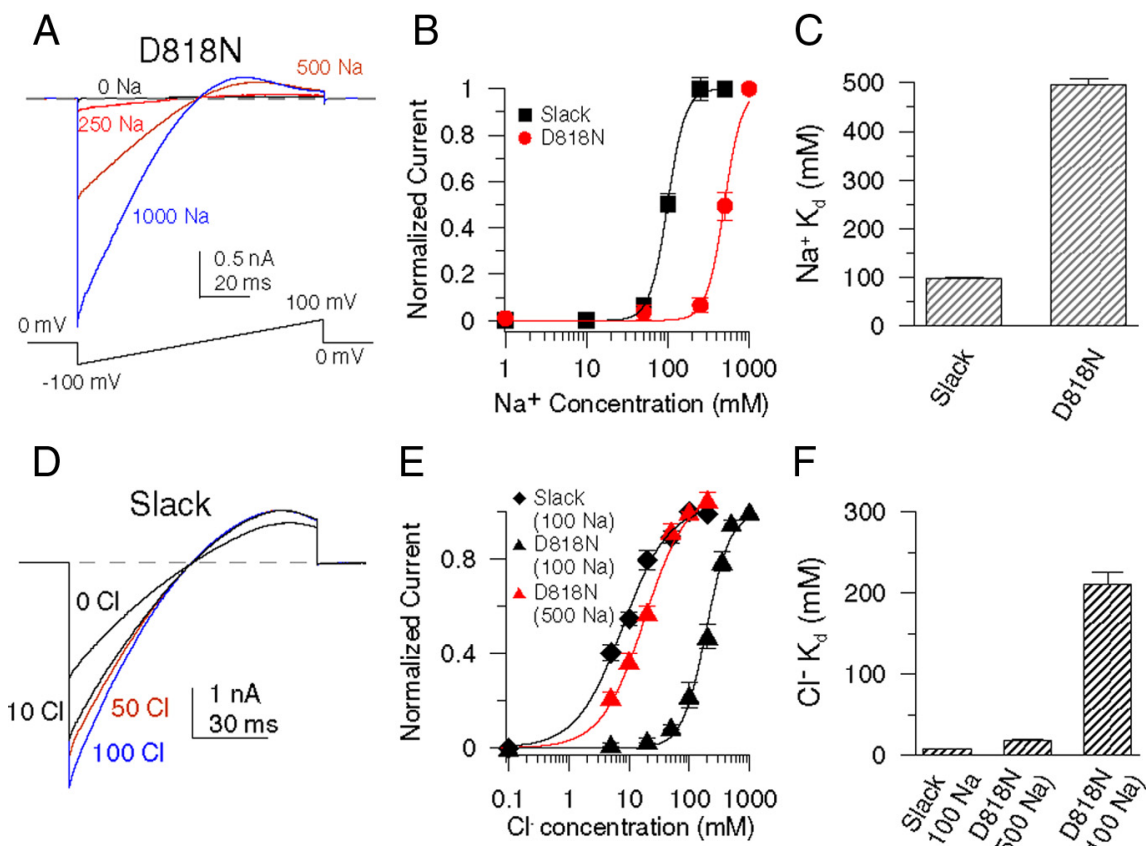

$\mathrm{F}$

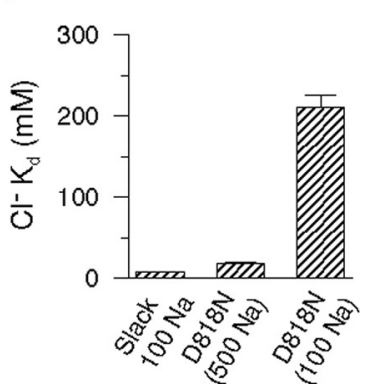

Figure 3. The change in $\mathrm{Na}^{+}$sensitivity of $\mathrm{D} 818 \mathrm{~N}$ is independent of $\mathrm{Cl}^{-} . \boldsymbol{A}$, Typical current traces recorded in the inside-out patch configuration for D818N. The bath solution was BS2. B, Na ${ }^{+}$dose-response for the wild-type Slack channel and the D818N mutant. Data were fitted with the Hill equation. $C$, Summary of $K_{\mathrm{d}}$ values for the wild-type Slack $\left(K_{\mathrm{d}}\right.$ of $\left.99.1 \pm 2.3 \mathrm{~mm}, n=4.0\right)$ and the D818N mutant $\left(K_{\mathrm{d}}\right.$ of $\left.496.1 \pm 11.7 \mathrm{~mm}, n=4.0\right)$ in $0 \mathrm{~mm} \mathrm{Cl}^{-}$. D. Typical current traces recorded in the inside-out patch configuration for Slack. The bath solution was BS3.E, $\mathrm{Cl}^{-}$dose-response for the wild-type Slack channel and D818N mutant in 100 $\mathrm{mm} \mathrm{Na}^{+}$and the D818N mutant in $500 \mathrm{~mm} \mathrm{Na}^{+}$. Data were fitted with the Hill equation. $\boldsymbol{F}$, Summary of $K_{\mathrm{d}}$ values for the wild-type Slack $\left(K_{\mathrm{d}}\right.$ of $\left.7.9 \pm 0.8 \mathrm{~mm}, n=1.12\right)$ and D818N $\left(K_{\mathrm{d}}\right.$ of $\left.210.7 \pm 14.1 \mathrm{~mm}, n=1.1\right)$ in $100 \mathrm{~mm} \mathrm{Na}{ }^{+}$and the D818N mutant $\left(K_{\mathrm{d}}\right.$ of $18.2 \pm 3.9 \mathrm{~mm}, n=1.2)$ in $500 \mathrm{~mm} \mathrm{Na}^{+}$.

sibility of some deviation from the Kir sodium binding motif was taken into account during the design of the potential $\mathrm{Na}^{+}$binding sites in Slack. The Asp residues in these potential sites were neutralized to Asn to test whether these mutants affected the sensitivity of Slack channels to $\mathrm{Na}^{+}$. We applied a ramp voltage protocol from -100 to $+100 \mathrm{mV}$ in inside-out patch-clamp recordings. Both currents from wild-type and mutant Slack channels exhibited sodium-dependent inward rectification attributable to voltage-dependent block by $\mathrm{Na}^{+}$(Fig. 1C,D). The current level at $-90 \mathrm{mV}$ in different $\mathrm{Na}^{+}$concentrations was used to assess the sensitivity of wild-type and mutant Slack channels to $\mathrm{Na}^{+}$. The current levels measured in different $\mathrm{Na}^{+}$concentrations were normalized to the current level at $500 \mathrm{mM} \mathrm{Na}^{+}$. Of the six putative $\mathrm{Na}^{+}$-binding sites, four mutants, D382N, D549N, D444N, and D761N, decreased Slack channel sensitivity to $\mathrm{Na}^{+}$only slightly ( $K_{\mathrm{d}}$ value increased less than twofold), whereas one mutant, D485N, showed the same sodium sensitivity as that of the wild-type Slack. In contrast, the D $818 \mathrm{~N}$ mutant dramatically decreased Slack sensitivity to $\mathrm{Na}^{+}$more than fourfold (Fig. $1 E, F)$. Moreover, the $\mathrm{D} 382 \mathrm{ND} 818 \mathrm{~N}$ double mutation did not show an additional decrease in sensitivity to $\mathrm{Na}^{+}$compared with $\mathrm{D} 818 \mathrm{~N}$ (data not shown), suggesting that D818 is a major determinant of $\mathrm{Na}^{+}$sensitivity in Slack channels.

We then asked whether the residues around D818 conformed to the Kir consensus site by performing alanine scanning mutagenesis and testing for effects on $\mathrm{Na}^{+}$sensitivity. We used a ramp protocol again and plotted the current values at $-90 \mathrm{mV}$ as a function of internal $\mathrm{Na}^{+}$concentration (Fig. 2D). Typical traces and normalized currents of V814A, D818N, and H823A fitted with the Hill equation are also shown (Fig. $2 A-C$ ). The D818A mutant was not functional (data not shown). Our results illustrate that the $K_{\mathrm{d}}$ values of the sodium sensitivities of mutants neighboring the D818 residue were not significantly changed, with the exception of H823A (Fig. 2D,E). These results suggest that Slack channels share with Kir channels an $\mathrm{Na}^{+}$coordination site that is located in their RCK2 domain. The K820A mutation showed no effect on the $\mathrm{Na}^{+}$sensitivity of the channel. In Kir channels, mutation of an Arg residue corresponding to K820 greatly reduces channel activity. Sequence comparison suggests that this site is not intact in the Slick channel (Fig. 1A). Because the Slick channel is also $\mathrm{Na}^{+}$sensitive and the Slack channel retains a weak sodium dependence even after mutagenesis of the D818N/H823N sites, the existence of additional sodium binding sites is likely. Multiple sites for ion sensing are not surprising considering that the Slo1 $\mathrm{Ca}^{2+}$-activated potassium channel, which belongs to same channel family, possesses three distinct $\mathrm{Ca}^{2+}$ binding sites that regulate its activity (Zeng et al., 2005).

Because Slack channels are also sensitive to $\mathrm{Cl}^{-}$and $\mathrm{Na}^{+}$and $\mathrm{Cl}^{-}$sensitivities show an intricate interdependence (Yuan et al., 2003), we investigated the $\mathrm{Na}^{+}$sensitivity of $\mathrm{D} 818 \mathrm{~N}$ in the absence of $\mathrm{Cl}^{-}$. The $90 \mathrm{~mm} \mathrm{KCl}$ was replaced by $90 \mathrm{~mm}$ KGlu in both our bath and pipette solutions. Typical current traces of $\mathrm{D} 818 \mathrm{~N}$ under this condition are shown in Figure $3 A$. Current levels recorded at $-90 \mathrm{mV}$ were normalized to currents recorded in $250 \mathrm{mM} \mathrm{Na}^{+}$(Slack) and $1000 \mathrm{mM} \mathrm{Na}^{+}(\mathrm{D} 818 \mathrm{~N})$, respectively. Normalized currents were plotted and fitted by the Hill equation (Fig. $3 B$ ). Both the $K_{\mathrm{d}}$ value of the wild-type Slack channel and the D $818 \mathrm{~N}$ mutant were increased in the absence of $\mathrm{Cl}^{-}$, however, the $K_{\mathrm{d}}$ value of D $818 \mathrm{~N}$ to $\mathrm{Na}^{+}$remained approximately fivefold higher than the value of the wild-type Slack channel (Fig. $3 C$ ). Our results suggest that the effect of D818N on the $\mathrm{Na}^{+}$sensitivity of the channel can operate independently of $\mathrm{Cl}^{-}$. To assess a potential influence of the D818 $\mathrm{N}_{\text {on }} \mathrm{Cl}^{-}$sensitivity, we performed inside-out patch-clamp recordings with different $\mathrm{Cl}^{-}$concentrations in the bath solution. Our results on wild-type Slack currents agree with previous reports (Yuan et al., 2003), showing that, in a $100 \mathrm{~mm}$ sodium solution, the $K_{\mathrm{d}}$ value of the Slack channel for $\mathrm{Cl}^{-}$was $7.9 \pm 0.8$ $\mathrm{mm}$ (data were fitted with the Hill equation; $n=1.1$ ) (Fig. $3 D-F)$. Not surprisingly, the D $818 \mathrm{~N}$ mutant also dramatically decreased the $\mathrm{Cl}^{-}$sensitivity of the channel. The $K_{\mathrm{d}}$ value of D818 $\mathrm{N}_{\text {for }} \mathrm{Cl}^{-}$ was $210 \pm 14.3 \mathrm{~mm}$ in $100 \mathrm{~mm} \mathrm{Na}^{+}$, with a concomitant increase in the Hill coefficient factor $(n=1.9)$. This result suggests that disruption of an $\mathrm{Na}^{+}$regulatory site decreased $\mathrm{Cl}^{-}$sensitivity more than 25-fold, further underscoring the intricate coupling mechanism between $\mathrm{Na}^{+}$and $\mathrm{Cl}^{-}$sensitivities in Slack channels. Because $\mathrm{Cl}^{-}$sensitivity of Slack depends on $\mathrm{Na}^{+}$sensitivity, we further compared the effect of the D818N mutant on $\mathrm{Cl}^{-}$sensitivity in $500 \mathrm{mM} \mathrm{Na}^{+}$concentration, which provides a similar open probability for D818N as the open probability seen with the wild-type Slack channel in $100 \mathrm{~mm} \mathrm{Na}^{+}$. Our results show that the $\mathrm{Cl}^{-}$sensitivity of D818N was only approximately twofold less than the wild-type Slack channel in this condition. The $K_{\mathrm{d}}$ was 
A Slo2.2
Iid1 Slo2.2 lid1

\section{Slo2.2 DHHFLEAICCF - PMVYYMEGSV lid1 EDDI KQLEQRLGDNADVI PGDS $: \ldots:$ : : . : * .}

Slo2.2 DNLDSLLOCGI IYADNLVVVDKE Iid1 NDSSVLKKAGIDRCRAILALSDN $::$ * $^{*}$ * $:: \ldots: \ldots$ :

C

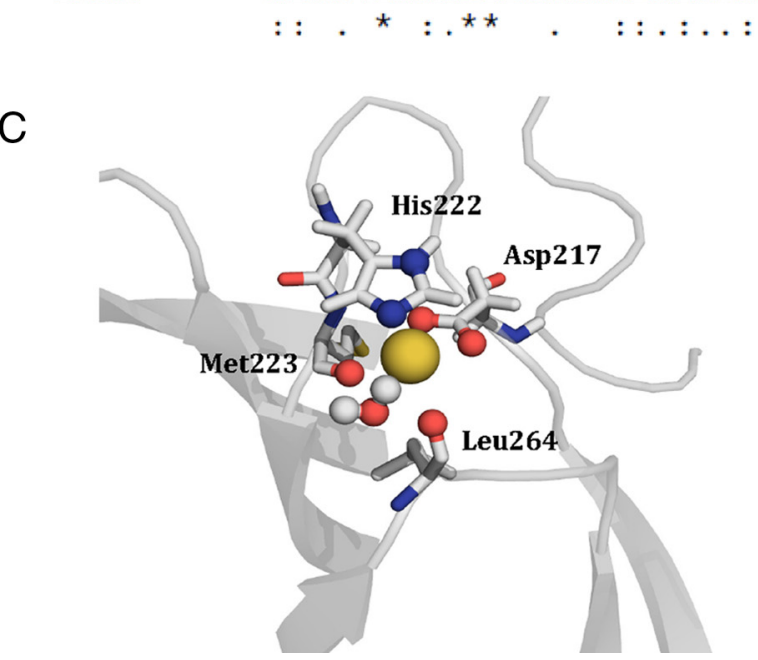

KNKLIIVSAETAGNGLYNF IVP KDHFIVC - - - -GHS I LAINTI

LRAYYRSRRELNPIVLLLDNKP LQLNQRGQ - N - - - VTVISNLP

*: *.: : $:$ * : : .**
B
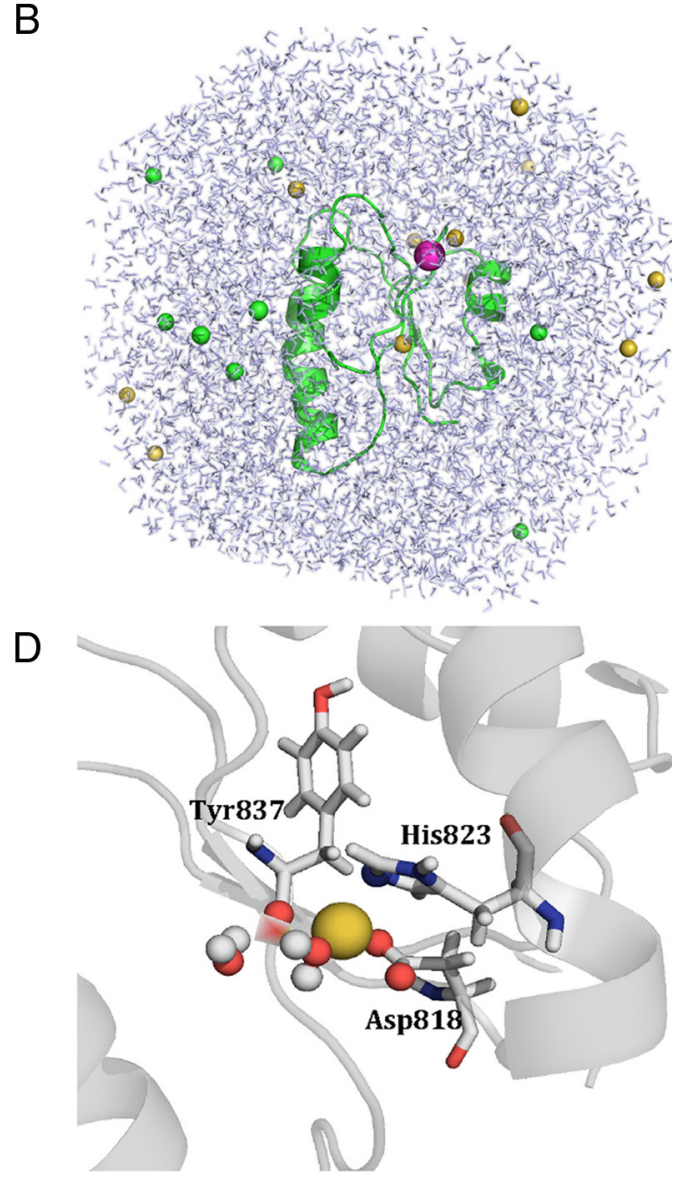

Figure 4. A model of the $\mathrm{Na}^{+}$coordination site of Slack. A, Sequence alignment between the RCK domain from an $E$. coli $\mathrm{K}^{+}$channel and the Slack used to construct a homology model. $\boldsymbol{B}$, Example of the simulation system for MD studies of C terminus of Slack channel in explicit $100 \mathrm{~mm} \mathrm{NaCl}$ (green and yellow spheres). Bound sodium ion shown in magenta. C, Simulated structure for the equilibrated sodium binding site in the C terminus of Kir3.1(N217D). D, Simulated structure for the equilibrated sodium binding site in the C terminus of Slack.

$18.2 \pm 3.9 \mathrm{~mm}$ (Fig. $3 E, F)$. These results show that the $\mathrm{Cl}^{-}$ sensitivity of Slack could be changed modestly with increasing $\mathrm{Na}^{+}$concentrations in the $\mathrm{D} 818 \mathrm{~N}$ background, suggesting either some contribution from additional $\mathrm{Na}^{+}$regulatory sites or that the side chain of $818 \mathrm{~N}$ could still play a role in coupling to $\mathrm{Cl}^{-}$ sensitivity, considering that D818A was not functional.

\section{Theoretical and experimental binding affinities for $\mathrm{Na}^{+}$: comparison between the cytosolic domain of Kir3.1 and the predicted site in Slack}

A homology model of the RCK2 domain of Slack was constructed, using as a template the structure of a prokaryotic RCK domain (Jiang et al., 2001) (Fig. 4A). We analyzed a $10 \mathrm{~ns}$ trajectory for the $\mathrm{Na}^{+}$-loaded Kir3.1N217D and Slack proteins in explicit solvent. Examples of the simulation system and ion binding pockets are shown in Figure $4 B-D$, respectively. The RMS fluctuations for heavy atoms were $\sim 2 \AA$ for both structures, indicating high stability for the MD simulations in both systems. The results for monovalent cation selectivity of the tentative binding sites located in the C terminus of the Kir3.1N217D and Slo2.2 channels are shown in Table 1. The sodium ion is stable residing in the tentative binding site for the entire course of the MD simulation ( $>10$ ns for both systems), which is expected from reported experimental data indicating at least millimolar binding affinity to the tentative site (Sui et al., 1996; Ho and MurrellLagnado, 1999b). The site is open to solvent access, and water is transiently present in the first coordination shell of the ion. Our
Table 1. The relative free energy of $\mathrm{Na}^{+}$selectivity of the binding site in the C terminus of Kir3.1N217D and wild-type Slo2.2

\begin{tabular}{llc}
\hline & $\Delta \Delta G_{\mathrm{Na}+/ \mathrm{K}+}$ & $\Delta \Delta G_{\mathrm{Na}+/ \mathrm{Li}+}$ \\
\hline Kir3.1 & 2.9 & 1.1 \\
Slo2.2 & 2.5 & 0.8 \\
D818R & $\mathrm{N} / \mathrm{A}$ & $\mathrm{N} / \mathrm{A}$ \\
D818E & 1.9 & -0.2 \\
D818N & 1.1 & 4.9 \\
\hline
\end{tabular}

All units are in kilocalories per moles. The positive sign in the relative free energy $(\Delta \Delta G)$ refers to site preferences for $\mathrm{Na}^{+}$.

analysis indicates that the $\mathrm{Na}^{+}$ion in the Slack site is coordinated by at least four residues and one water molecule (Fig. $4 D$ ). This partial hydration pattern is similar to that found in numerous previous reports on ion binding to external sites in the KcsA and NaK channels (Noskov and Roux, 2007). Both sites in the crystal and homology modeled structures display robust selectivity for $\mathrm{Na}^{+}$against $\mathrm{K}^{+}$. This can be explained by the presence of a negatively charged residue such as D818 (Slo2.2) in the first coordination shell of the ion in agreement with the "field-strength" theory proposed in the mid-60s by George Eisenman (1962). A smaller cation such as $\mathrm{Na}^{+}$would interact more favorably with the binding site containing charged ligand such as carboxylate (Eisenman, 1962; Noskov et al., 2004). In the absence of $\mathrm{Na}^{+}$, the interactions of K820 and D818 were stabilized through hydrogen bonding [an average distance of $1.8 \pm 0.24 \AA$ between the $\mathrm{OD}^{*}$ (carboxylate oxygen)-HZ ${ }^{\star}$ (a hydrogen in a charged amino group)], 
A

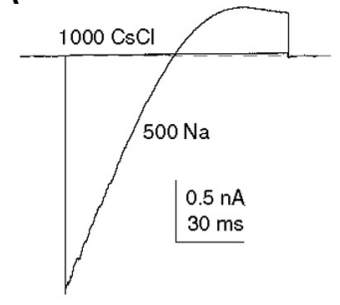

B

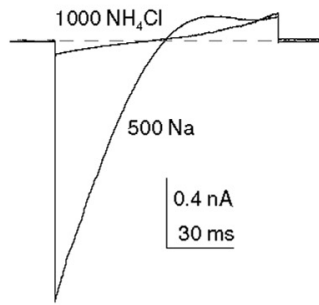

$\mathrm{E}$
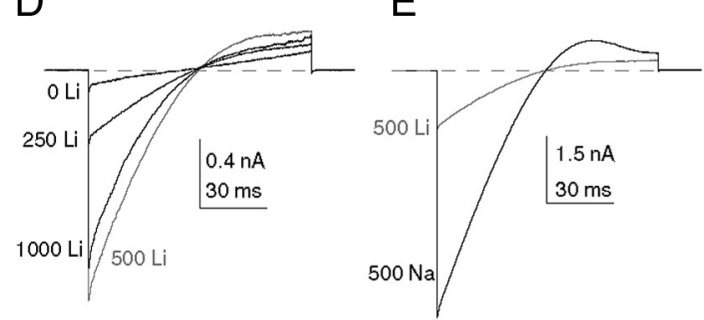

C

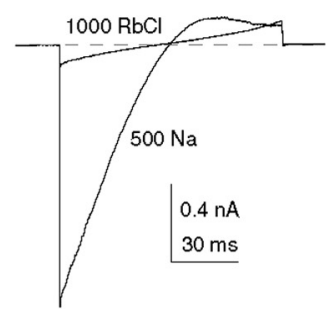

$\mathrm{F}$

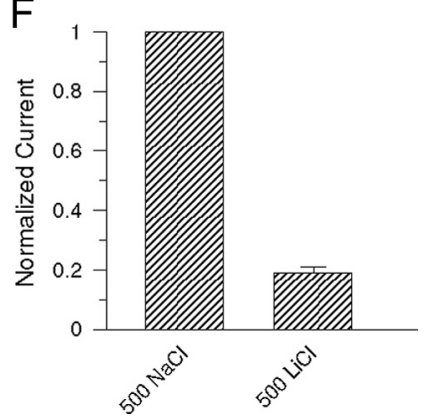

Figure 5. $\mathrm{Li}^{+}$activates the Slack channel in a dose-dependent manner. $\mathbf{A}-\mathbf{C}$, Typical current traces recorded in the inside-out patch configuration for Slack channel in $\mathrm{Cs}^{+}, \mathrm{NH}_{4+}$, and Rb ${ }^{+}$, respectively. $\mathrm{BS} 1$ plus $1 \mathrm{M} \mathrm{CSCl}, 1 \mathrm{M} \mathrm{NH}_{4} \mathrm{Cl}$, and $1 \mathrm{M} \mathrm{RbCl}$, respectively. The pipette solution included $90 \mathrm{~mm} \mathrm{KCl}, 10 \mathrm{~mm}$ HEPES-K, and $5 \mathrm{~mm}$ EGTA-K. D. Current traces recorded with -100 to $+100 \mathrm{mV}$ ramp protocol in inside-out patch configuration. Bath solution includes $0-1000 \mathrm{~mm} \mathrm{LiCl}$. Other solution components were the same as indicated above. $\boldsymbol{E}$, The same trace shown in $\boldsymbol{D}$ with $500 \mathrm{~mm}$ LiCl is shown in a different scale (gray) together with the trace recorded in $500 \mathrm{~mm} \mathrm{NaCl}$. , Bar graph summaries showing the level of currents recorded in $500 \mathrm{~mm}$ LiCl relative to those recorded in $500 \mathrm{~mm} \mathrm{NaCl}$.

A

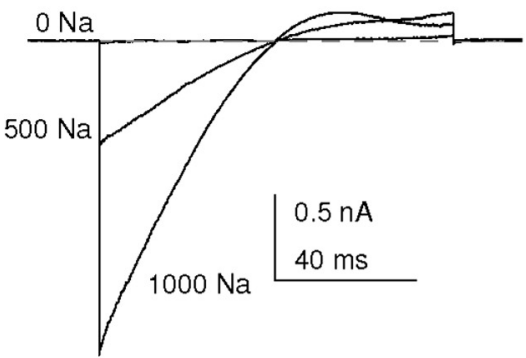

C

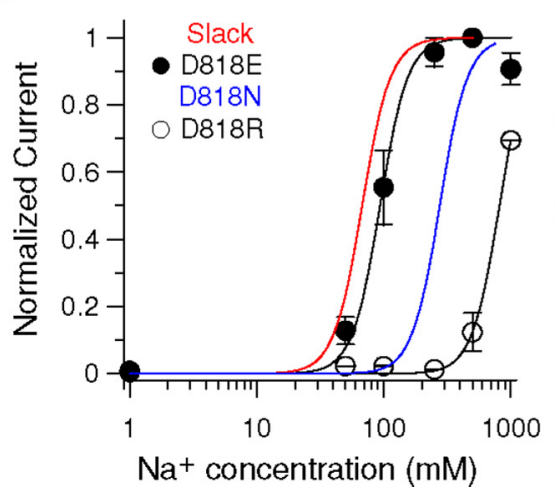

B

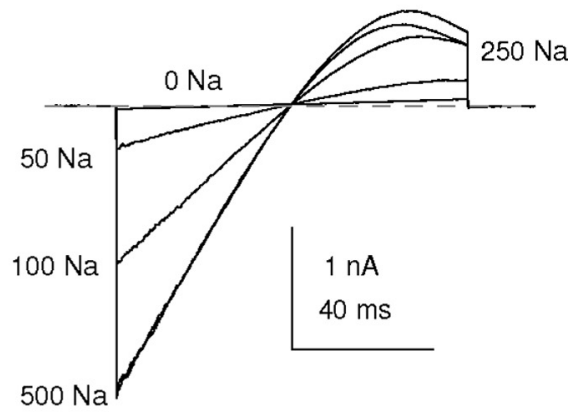

D

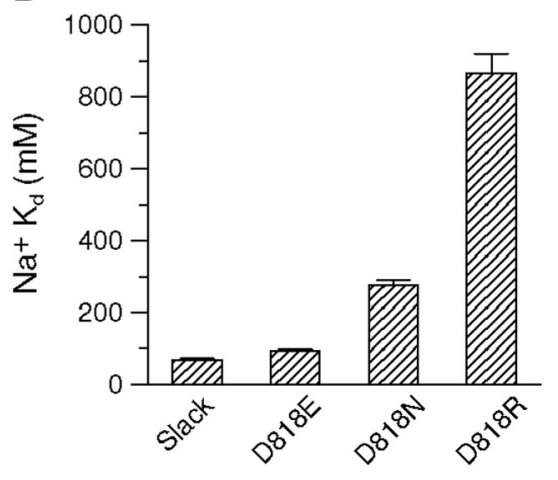

Figure 6. The D818R mutant shows a $>10$-fold decrease in $\mathrm{Na}^{+}$sensitivity, whereas the D818E mutant shows a similar $\mathrm{Na}^{+}$ sensitivity to the wild-type Slack channel. $\boldsymbol{A}, \boldsymbol{B}$, Current traces recorded by ramp protocol from D818R and D818E, respectively. The bath solution was BS1.C, Sodium dose-response of D818E $\left(K_{\mathrm{d}}\right.$ of $\left.93 \pm 4.5 \mathrm{~mm}, n=4\right)$ and D818R $\left(K_{\mathrm{d}}\right.$ of $\left.866 \pm 54 \mathrm{~mm}, n=4\right)$. Data were fitted with the Hill equation. D, Bar graph summaries of $K_{d}$ values of wild-type Slack and mutant channels (D818E, D818N, and D818R).

present in $92 \%$ of the frames with an average interaction energy of $-92.3 \mathrm{kcal} / \mathrm{mol}$ ). $\mathrm{Na}^{+}$ destabilized this interaction between $\mathrm{K} 820$ and D818 (an average distance of $2.7 \AA$ between the $\mathrm{OD}^{\star}-\mathrm{HZ}^{*}$, present in $\sim 75 \%$ of the frames with an average interaction energy of $-76.2 \mathrm{kcal} / \mathrm{mol}$ showing a large dispersion).

Our simulations on relative free energies of $\mathrm{Na}^{+}$versus $\mathrm{Li}^{+}$also predicted that this regulatory site in the $\mathrm{C}$ terminus of Slo2.2 can potentially be occupied by $\mathrm{Li}^{+}$ but with weaker affinity than $\mathrm{Na}^{+}$. The absolute binding affinities for a particular cation are difficult to calculate with FEP methods in part as a result of difficulties in sampling of ion dynamics for ending points of perturbation, in which the ion is fully uncoupled from the protein binding site (Deng and Roux, 2009; Mobley and Dill, 2009). At the same time, the accuracy in FEP results for monovalent cation affinity is known to be around $\pm 1 \mathrm{kcal} / \mathrm{mol}$ and provides a robust measure of the difference in binding affinities between different cations (Noskov et al., 2004; Noskov and Roux, 2007). $\mathrm{Li}^{+}$, unlike $\mathrm{Na}^{+}$, was not stable in the site and tended to escape to the bulk solution. To prevent ion escape from the binding site, weak structural constraints were used in all simulations with an $\mathrm{Li}^{+}$ion. The ion was confined within a sphere with radius of $3.5 \AA$ using a flat-bottom harmonic restraining potential with a force constant of $5 \mathrm{kcal} /$ mol/A (Noskov and Roux, 2007).

We proceeded to test for $\mathrm{Li}^{+}$effects in an electrophysiological experiment. The typical current traces recorded from insideout patches using a voltage-ramp protocol in high concentrations of $\mathrm{Cs}^{+}, \mathrm{NH}_{4}^{+}$, or $\mathrm{Rb}^{+}$are shown in Figure $5 A-C$. None of these ions could significantly activate Slack currents in concentrations starting from $50 \mathrm{~mm}$ up to $1 \mathrm{M}$ in macroscopic or unitary current recordings. $\mathrm{Rb}^{+}$is the ion most similar to $\mathrm{K}^{+}$and is often used in studies of selectivity. The lack of activation in the presence of $\mathrm{Rb}^{+}$is in good accord with the apparent $\mathrm{Na}^{+}$selectivity of the predicted binding site. $\mathrm{Li}^{+}$activated the Slack channel in a dose-dependent manner (Fig. 5D). Moreover, compared with $\mathrm{Na}^{+}, \mathrm{Li}^{+}$exhibited a weaker potency in activating Slack currents (Fig. 5E). At a concentration of $500 \mathrm{mM}, \mathrm{Li}^{+}$activated Slack currents at $\sim 20 \%$ compared with $\mathrm{Na}^{+}$(Fig. 5E,F). These results were consistent with our predictions of constrained simulations evaluating $\mathrm{Na}^{+} / \mathrm{Li}^{+}$selectivity of this site.

Because D818 is a negatively charged residue that can form electrostatic inter- 


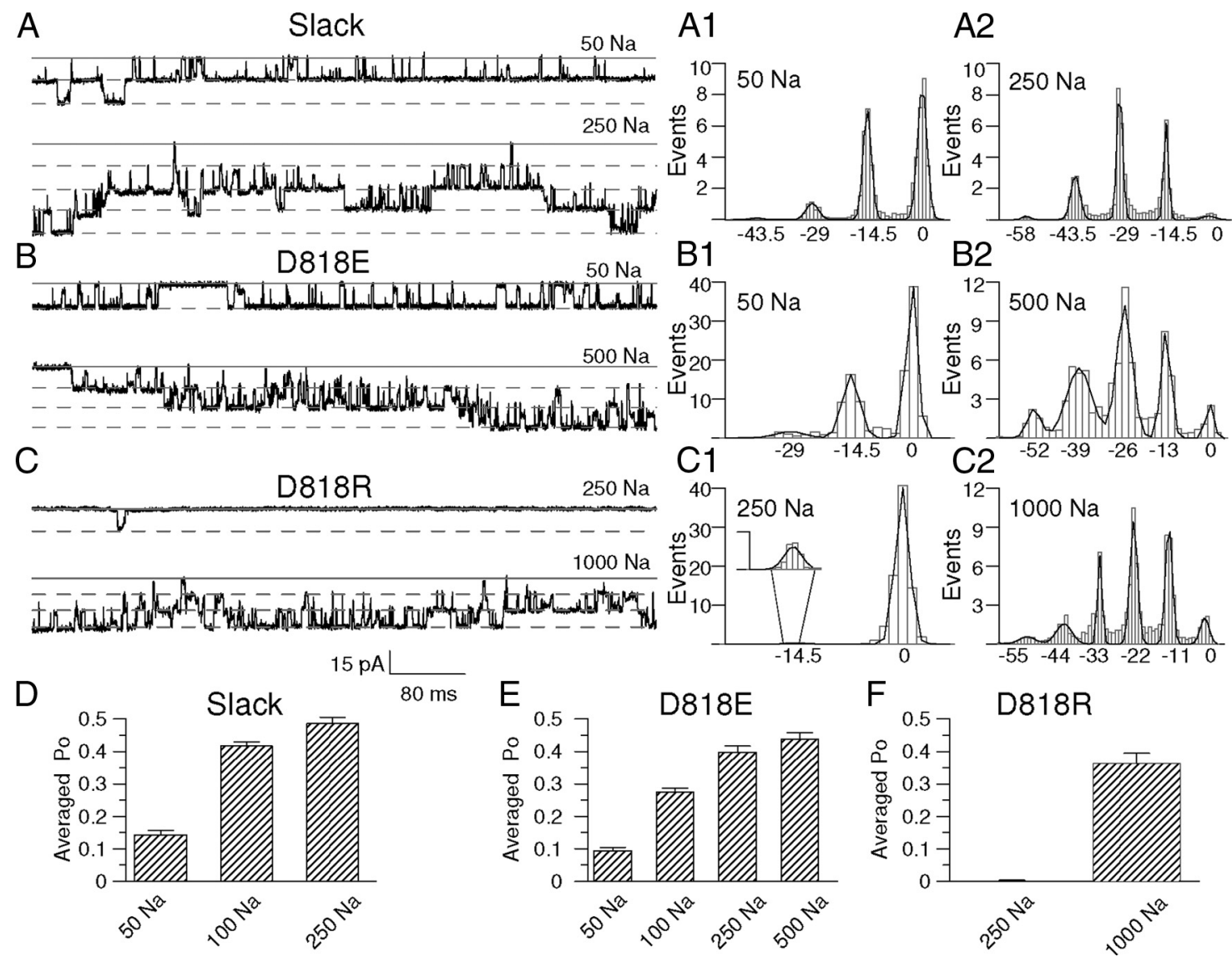

Figure 7. $\mathrm{Na}^{+}$sensitivity of unitary currents of wild-type Slack and D818E and D818R mutant channels. Sample single-channel traces measured at $-100 \mathrm{mV}$ at different $\mathrm{Na}{ }^{+}$concentrations in the inside-out patch-clamp configuration for wild-type Slack. $\boldsymbol{A}, \mathrm{D} 818 \mathrm{E} ; \boldsymbol{B}, \mathrm{D} 818 \mathrm{R} ; \boldsymbol{C}$, total events were fitted by a Gaussian functions. $\boldsymbol{A 1}$, Slack with $50 \mathrm{~mm} \mathrm{Na}{ }^{+} ; \boldsymbol{A 2}$, Slack with $250 \mathrm{~mm} \mathrm{Na}{ }^{+} ; \boldsymbol{B} 1$, D818E with $50 \mathrm{~mm} \mathrm{Na}^{+} ; B 2$, D818E with $500 \mathrm{~mm} \mathrm{Na}^{+} ; C 1$, D818R with $250 \mathrm{~mm} \mathrm{Na}^{+} ; \mathbf{C 2}, \mathrm{D} 818 \mathrm{R}$ with $1000 \mathrm{~mm} \mathrm{Na}{ }^{+}$. Each number in the $y$-axis is times 10,000 events. The unit in the $y$-axis of the $C 1$ inset stands for 4000 events. $x$-axes labels show the current level in picoamperes. Averaged $P_{0}$ values in different sodium concentrations of Slack $\left(50 \mathrm{~mm} \mathrm{Na}^{+}, P_{0}=0.14 \pm 0.013 ; 100 \mathrm{~mm} \mathrm{Na}{ }^{+}\right.$, $\left.P_{0}=0.42 \pm 0.014 ; 250 \mathrm{~mm} \mathrm{Na}^{+}, P_{0}=0.48 \pm 0.02\right), D 818 \mathrm{E}\left(50 \mathrm{~mm} \mathrm{Na}{ }^{+}, P_{0}=0.09 \pm 0.01 ; 100 \mathrm{~mm} \mathrm{Na}^{+}, P_{0}=0.27 \pm 0.014 ; 250 \mathrm{~mm} \mathrm{Na}^{+}, P_{0}=0.4 \pm 0.02 ; 500 \mathrm{~mm} \mathrm{Na}{ }^{+}, P_{0}=0.44 \pm\right.$ $0.02)$, and D818R ( $\left.250 \mathrm{~mm} \mathrm{Na}^{+}, P_{0}=0.002 \pm 0.001 ; 1000 \mathrm{~mm} \mathrm{Na}^{+}, P_{0}=0.36 \pm 0.03\right)$ were summarized in $\boldsymbol{D}, \boldsymbol{E}$, and $\boldsymbol{F}$, respectively.

actions with positive charges, such as in $\mathrm{Li}^{+}$and $\mathrm{Na}^{+}$, we tested whether this electrostatic interaction plays a major role in the binding with $\mathrm{Na}^{+}$. The results of FEP simulations on Slack mutants are shown also in Table 1. Neutralization of the charge in position 818 by mutating the aspartate to an asparagine had a notable impact on the stability of bound sodium ion in the binding site as well as on the selectivity for $\mathrm{Na}^{+}$. The reversal of the charge $(D / R)$ mutation led to a very unstable binding site and large harmonic constraints $\left(100 \mathrm{kcal} / \mathrm{mol} / \AA^{2}\right)$ were required to keep the ion in the site. At the same time, a mutation conserving the charge (D/E) had no statistically significant effects on the ion selectivity of this binding site in free energy simulations.

We followed up to experimentally test the predictions of the FEP simulations for the D818 mutants. The D818R mutation further decreased Slack sensitivity to $\mathrm{Na}^{+}$compared with D818N. With $500 \mathrm{~mm} \mathrm{Na}^{+}$, channel activation was still very low, but with $1 \mathrm{M} \mathrm{Na}^{+}$, it showed a significant increase still not reaching the maximum (Fig. 6A). Hill equation fits gave an estimate of the $K_{\mathrm{d}}$ for $\mathrm{D} 818 \mathrm{R}$ of $\sim 866 \pm 154 \mathrm{~mm}$ (keeping the Hill equation coefficient factor as 4 and using the largest fitted current as 1 to normalize different macropatches) (Fig. 6C). In contrast, when the negative charge was retained by mutating the D to E, the $K_{\mathrm{d}}$ was only slightly higher than wild type $\left(\mathrm{EC}_{50}\right.$ of $80 \pm 10 \mathrm{~mm}$ ) (Fig. $6 B, C)$. The bar graph shown in Figure $6 D$ summarizes the $K_{\mathrm{d}}$ values for mutations at this site.
We further tested the $\mathrm{Na}^{+}$sensitivity of the wild-type Slack, D818E, and D818R at the single-channel level at $-100 \mathrm{mV}$. No differences in unitary conductance were observed among the wildtype Slack and the mutants D818E and D818R. The unitary conductance of these channels in ND96 was $\sim 145 \mathrm{pS}$, consistent with previously reported results (Yuan et al., 2003; Chen et al., 2009). The open probability of these channels increased with increasing $\mathrm{Na}^{+}$ concentrations (Fig. 7A-C). As shown in the sample traces, the wild-type channel (at $250 \mathrm{mM} \mathrm{Na}^{+}$) and the D818E mutant (at $500 \mathrm{mM} \mathrm{Na}^{+}$) exhibited saturated $n P_{\mathrm{o}}$ values of 1.64 and 1.72 , respectively, whereas there were a total of four discrete observed channel levels. However, for D818R, the saturated $n P_{\mathrm{o}}$ was $1.82(1000 \mathrm{~mm} \mathrm{Na})$ when there were a total of five discrete observed channel levels. The averaged $P_{\mathrm{o}}$ from different patches was calculated by using the largest number of simultaneously open channels that was seen in the records. The saturated $P_{\mathrm{o}}$ of Slack and D818E was $0.48 \pm 0.02$ and $0.44 \pm$ 0.02 , respectively, whereas the saturated $P_{\mathrm{o}}$ of $\mathrm{D} 818 \mathrm{R}$ was $0.36 \pm 0.03$ (Fig. $7 D-F$ ). These results show that D818R saturated open probability is still lower than that of $\mathrm{D} 818 \mathrm{E}$ or the wild-type Slack even when the patches were perfused with much higher concentrations of $\mathrm{Na}^{+}$. These results of the unitary activity of Slack were consistent with those obtained from macropatch recordings and FEP simulations. 


\section{Discussion}

It has been shown previously that three Kir channels (Kir3.2, Kir3.4, and Kir5.1) possess an $\mathrm{Na}^{+}$sensor that endows them with $\mathrm{Na}^{+}$sensitivity even in heteromeric assemblies they form with other channel subunits that lack the $\mathrm{Na}^{+}$sensor (RosenhouseDantsker et al., 2008). MD simulations and mutagenesis experiments, based on crystallographic structures, showed that the Kir $\mathrm{Na}^{+}$sensor partly comprises the side chains of an aspartate and a histidine that are located across from one another in a cytosolic loop (Rosenhouse-Dantsker et al., 2008). This part of the coordination site forms a motif found in the three $\mathrm{Na}^{+}$-sensitive Kir channels, DXRXXH, which can operate even in $\mathrm{Na}^{+}$insensitive Kir channels, when engineered by mutagenesis (e.g., Kir3.1N217D or Kir2.1N216D) (Ho and Murrell-Lagnado, 1999a; Zhang et al., 1999). In the current study, screening the C terminus of Slo2.2 for the presence of this $\mathrm{Na}^{+}$-sensing motif revealed several possible sites, and mutagenesis confirmed that one such motif localized in the RCK2 domain of Slo2.2 operated as an $\mathrm{Na}^{+}$sensor. Again the aspartate and the histidine side chains were key elements of the Slo2.2 $\mathrm{Na}^{+}$coordination site. Free energy calculations were also consistent with experimental data regarding cation selectivity or the behavior of mutants of the critical Asp (D818E, D818N, and D818R). These results provide compelling evidence that a conserved local structural element of an $\mathrm{Na}^{+}$sensor is used by distinct potassium channels with different general structures.

For Kir channels, mutation of the conserved arginine residue in the $\mathrm{Na}^{+}$-sensing motif greatly reduced channel activity. Indeed, this Arg residue has been shown by a number of studies and in different Kir channels to be critical for interactions with phosphatidylinositol-bisphosphate $\left(\mathrm{PIP}_{2}\right)$ and its mutation to inhibit activity and cause the condition known as Andersen's syndrome (e.g., for Kir2.1, R218Q or R218W) (Zhang et al., 1999; Lopes et al., 2002; Pegan et al., 2005). In the absence of $\mathrm{Na}^{+}$, the Asp could hydrogen bond with the Arg and prevent it from interacting with $\mathrm{PIP}_{2}$, thus keeping the channel inactive. In the presence of $\mathrm{Na}^{+}$, however, the Asp would switch to coordinate the $\mathrm{Na}^{+}$ion, thus leaving the Arg free to interact with $\mathrm{PIP}_{2}$ and activate the channel (Rosenhouse-Dantsker et al., 2008). In the Slo2.2 channel, there is a lysine in place of the Arg residue in the $\mathrm{Na}^{+}$-sensing motif. Mutation of K820 did not affect $\mathrm{Na}^{+}$sensitivity of Slo2.2 channels. However, like in Kir channels, the Slo2.2 K820 residue hydrogen bonds with D818 in the absence of $\mathrm{Na}^{+}$, whereas in the presence of $\mathrm{Na}^{+}$, this interaction is destabilized. The functional significance of this switching mechanism is not presently clear for Slo2.2 channels.

However, the mere location of the $\mathrm{Na}^{+}$-sensing motif in the RCK2 domain is intriguing. The RCK (regulators of conductance of $\mathrm{K}^{+}$) domains are specialized intracellular structures found in many putative prokaryotic $\mathrm{K}^{+}$channels. The structure of the $\mathrm{Ca}^{2+}$-modulated bacterial channel MthK suggested formation of a gating ring composed of RCK1 and RCK2 domains, in which binding of $\mathrm{Ca}^{2+}$ was proposed to expand the ring, pull on the linkers that connected it to the channel gates, and thus open the channel (Jiang et al., 2002a). Similar models have been proposed for Slo1 channels (Niu et al., 2004), because $\mathrm{Ca}^{2+}$ and $\mathrm{Mg}^{2+}$ binding sites to the RCK1 domain have been reported (Xia et al., 2002) and have been shown to contribute significantly to $\mathrm{Ca}^{2+}$ sensitivity by a large number of studies (Salkoff et al., 2006; Cui et al., 2009). Thus, although additional important $\mathrm{Ca}^{2+}$-sensing sites have been identified, the contribution of the RCK1 domain to $\mathrm{Ca}^{2+}$ sensitivity is widely accepted. Our finding that yet an- other ion sensor, the Slo2.2 $\mathrm{Na}^{+}$sensor, is localized in the RCK2 domain of this channel provides additional credit to the notion that RCK domains are designed to couple distinct ion-sensing mechanisms to channel gating. Parallels with the Slo1 design of ion sensitivity may exist in Slo2.2 as well. Although mutations of the Asp and His residues in the identified RCK2 site were detrimental to $\mathrm{Na}^{+}$sensitivity, they did not abolish it, suggesting that additional sites may be involved in sensing $\mathrm{Na}^{+}$. Additional studies will be required, as has been the case with the Slo1 channels, to define the relationship of the RCK2 site to potential other ones and to discern how they couple to the channel gate. Finally, Slo2 channels show synergistic activation by both $\mathrm{Na}^{+}$and $\mathrm{Cl}^{-}$. Although the elimination of the RCK2 $\mathrm{Na}^{+}$site affected $\mathrm{Na}^{+}$sensitivity independently of the presence of $\mathrm{Cl}^{-}$, at the same time it greatly diminished the ability of $\mathrm{Cl}^{-}$to activate the channel. Thus, the RCK2 $\mathrm{Na}^{+}$site controls $\mathrm{Cl}^{-}$sensitivity but is not controlled by $\mathrm{Cl}^{-}$itself. This in an important constraint to consider as future studies aim to unravel the intricate interdependence of Slo2.2 on $\mathrm{Na}^{+}$and $\mathrm{Cl}^{-}$.

The physiological roles of $\mathrm{Na}^{+}$-sensitive channels continue to be increasingly appreciated. In heart, $\mathrm{K}_{\mathrm{Na}}$ may play an important protective role under ischemic conditions (Kameyama et al., 1984; Luk and Carmeliet, 1990; Mitani and Shattock, 1992). In neurons, their effects maybe dependent on a concomitant $\mathrm{Na}^{+}$ influx (Dryer, 1994), because they appear to be significant components of outward $\mathrm{K}^{+}$currents (Budelli et al., 2009), to regulate the accuracy of timing of auditory neurons (Yang et al., 2007), and to modulate rhythmic firing and adaptation (Brown et al., 2008). In kidney, Slo2.2 has been shown to be expressed in the medullary and cortical thick ascending limb of Henle's loop, one of the $\mathrm{Na}^{+}$reabsorbing segments of the nephron (Paulais et al., 2006). Interestingly, the remaining $\mathrm{Na}^{+}$reabsorbing segments of the nephron, the proximal and distal convoluted tubules, express the inwardly rectifying Kir5.1 $\mathrm{Na}^{+}$-sensitive channel. Thus, each $\mathrm{Na}^{+}$reabsorbing segment of the nephron possesses an $\mathrm{Na}^{+}{ }_{-}$ activated $\mathrm{K}^{+}$channel. Because a negative membrane potential of kidney tubular cells would contribute substantially toward $\mathrm{Na}^{+}$ reabsorption from the tubular lumen into the cell, $\mathrm{Na}^{+}$-sensitive $\mathrm{K}^{+}$channels could ensure that the membrane potential is maintained near the equilibrium potential for potassium. However, the purpose of using Slo2.2 versus Kir5.1 in specific nephron segments to achieve a negative membrane potential is likely to depend on characteristics of the individual channels rather than their similar $\mathrm{Na}^{+}$-sensing mechanism.

\section{References}

Bennett-Lovsey RM, Herbert AD, Sternberg MJ, Kelley LA (2008) Exploring the extremes of sequence/structure space with ensemble fold recognition in the program Phyre. Proteins 70:611-625.

Bhattacharjee A, Gan L, Kaczmarek LK (2002) Localization of the Slack potassium channel in the rat central nervous system. J Comp Neurol 454:241-254.

Bhattacharjee A, Joiner WJ, Wu M, Yang Y, Sigworth FJ, Kaczmarek LK (2003) Slick (Slo2.1), a rapidly-gating sodium-activated potassium channel inhibited by ATP. J Neurosci 23:11681-11691.

Brooks BR, Bruccoleri RE, Olafson BD, States DJ, Swaminathan S, Karplus M (1983) Charmm: a program for macromolecular energy, minimization, and dynamics calculations. J Comput Chem 4:187-217.

Brown MR, Kronengold J, Gazula VR, Spilianakis CG, Flavell RA, von Hehn CA, Bhattacharjee A, Kaczmarek LK (2008) Amino-termini isoforms of the Slack $\mathrm{K}^{+}$channel, regulated by alternative promoters, differentially modulate rhythmic firing and adaptation. J Physiol 586:5161-5179.

Budelli G, Hage TA, Wei A, Rojas P, Jong YJ, O’Malley K, Salkoff L (2009) $\mathrm{Na}^{+}$-activated $\mathrm{K}^{+}$channels express a large delayed outward current in neurons during normal physiology. Nat Neurosci 12:745-750.

Caplan DA, Subbotina JO, Noskov SY (2008) Molecular mechanism of ion- 
ion and ion-subtrate coupling in the NA+-dependent leucine trasporter LeuT. Biophys J 95:4613-4621.

Chen H, Kronengold J, Yan Y, Gazula VR, Brown MR, Ma L, Ferreira G, Yang Y, Bhattacharjee A, Sigworth FJ, Salkoff L, Kaczmarek LK (2009) The $\mathrm{N}$-terminal domain of Slack determines the formation and trafficking of Slick/Slack heteromeric sodium-activated potassium channels. J Neurosci 29:5654-5665.

Cui J, Yang H, Lee US (2009) Molecular mechanisms of BK channel activation. Cell Mol Life Sci 66:852-875.

Deng Y, Roux B (2009) Computations of standard binding free energies with molecular dynamics simulations. J Phys Chem B 113:2234-2246.

Dryer SE (1994) $\mathrm{Na}^{+}$-activated $\mathrm{K}^{+}$channels: a new family of largeconductance ion channels. Trends Neurosci 17:155-160.

Egan TM, Dagan D, Kupper J, Levitan IB (1992) $\mathrm{Na}^{+}$-activated $\mathrm{K}^{+}$channels are widely distributed in rat CNS and in Xenopus oocytes. Brain Res 584:319-321.

Eisenman G (1962) Cation selective electrodes and their mode of operation. Biophys J 2:259-323.

Essmann U, Perera L, Berkowitz ML, Darden T, Lee H, Pedersen LG (1995) A smooth particle mesh Ewald method. J Chem Phys 103:8577-8593.

Feller SE, Zhang YH, Pastor RW, Brooks BR (1995) Constant-pressure molecular-dynamics simulation: the Langevin piston method. J Chem Phys 103:4613-4621.

Gao SB, Wu Y, Lü CX, Guo ZH, Li CH, Ding JP (2008) Slack and Slick KNa channels are required for the depolarizing afterpotential of acutely isolated, medium diameter rat dorsal root ganglion neurons. Acta Pharmacol Sin 29:899-905.

Ho IH, Murrell-Lagnado RD (1999a) Molecular determinants for sodium-dependent activation of $\mathrm{G}$ protein-gated $\mathrm{K}^{+}$channels. J Biol Chem 274:8639-8648.

Ho IH, Murrell-Lagnado RD (1999b) Molecular mechanism for sodiumdependent activation of $\mathrm{G}$ protein-gated $\mathrm{K}^{+}$channels. J Physiol 520:645-651.

Jiang Y, Pico A, Cadene M, Chait BT, MacKinnon R (2001) Structure of the RCK domain from the E. coli $\mathrm{K}^{+}$channel and demonstration of its presence in the human BK channel. Neuron 29:593-601.

Jiang Y, Lee A, Chen J, Cadene M, Chait BT, MacKinnon R (2002a) Crystal structure and mechanism of a calcium-gated potassium channel. Nature 417:515-522.

Jiang Y, Lee A, Chen J, Cadene M, Chait BT, MacKinnon R (2002b) The open pore conformation of potassium channels. Nature 417:523-526.

Jin T, Peng L, Mirshahi T, Rohacs T, Chan KW, Sanchez R, Logothetis DE (2002) The (beta)gamma subunits of $G$ proteins gate a $\mathrm{K}^{+}$channel by pivoted bending of a transmembrane segment. Mol Cell 10:469-481.

Jo S, Lim JB, Klauda JB, Im W (2009) CHARMM-GUI membrane builder for mixed bilayers and its application to yeast membranes. Biophys J 97:50-58.

Kameyama M, Kakei M, Sato R, Shibasaki T, Matsuda H, Irisawa H (1984) Intracellular $\mathrm{Na}^{+}$activates a $\mathrm{K}^{+}$channel in mammalian cardiac cells. Nature 309:354-356.

Krivov GG, Shapovalov MV, Dunbrack RL Jr (2009) Improved prediction of protein side-chain conformations with SCWRL4. Proteins 77:778795.

Kumar S, Bouzida D, Swendsen RH, Kollman PA, Rosenberg JM (1992) The weighted histogram analysis method for free-energy calculations on biomolecules. 1. The method. J Comput Chem 13:1011-1021.

Lopes CM, Zhang H, Rohacs T, Jin T, Yang J, Logothetis DE (2002) Alterations in conserved Kir channel-PIP2 interactions underlie channelopathies. Neuron 34:933-944.

Luk HN, Carmeliet E (1990) Na+-activated $\mathrm{K}^{+}$current in cardiac cells: rectification, open probability, block and role in digitalis toxicity. Pflugers Arch 416:766-768.

Luzhkov VB, Aqvist J (2001) $\mathrm{K}^{+} / \mathrm{Na}^{+}$selectivity of the KcsA potassium channel from microscopic free energy perturbation calculations. Biochim Biophys Acta 1548:194-202.
Luzhkov VB, Almlöf M, Nervall M, Aqvist J (2006) Computational study of the binding affinity and selectivity of the bacterial ammonium transporter AmtB. Biochemistry 45:10807-10814.

Mitani A, Shattock MJ (1992) Role of Na-activated K channel, Na-K-Cl cotransport, and Na-K pump in $[\mathrm{K}] \mathrm{e}$ changes during ischemia in rat heart. Am J Physiol 263:H333-H340.

Mobley DL, Dill KA (2009) Binding of small-molecule ligands to proteins: "what you see" is not always "what you get." Structure 17:489-498.

Nanou E, El Manira A (2007) A postsynaptic negative feedback mediated by coupling between AMPA receptors and $\mathrm{Na}^{+}$-activated $\mathrm{K}^{+}$channels in spinal cord neurones. Eur J Neurosci 25:445-450.

Nanou E, Kyriakatos A, Bhattacharjee A, Kaczmarek LK, Paratcha G, El Manira A (2008) $\mathrm{Na}^{+}$-mediated coupling between AMPA receptors and KNa channels shapes synaptic transmission. Proc Natl Acad Sci U S A 105:20941-20946.

Niu X, Qian X, Magleby KL (2004) Linker-gating ring complex as passive spring and $\mathrm{Ca}^{2+}$-dependent machine for a voltage- and $\mathrm{Ca}^{2+}$-activated potassium channel. Neuron 42:745-756.

Noskov SY, Roux B (2007) Importance of hydration and dynamics on the selectivity of the KcsA and NaK channels. J Gen Physiol 129:135-143.

Noskov SY, Roux B (2008) Control of ion selectivity in LeuT: two Na+ binding sites with two different mechanisms. J Mol Biol 377:804-818.

Noskov SY, Bernèche S, Roux B (2004) Control of ion selectivity in potassium channels by electrostatic and dynamic properties of carbonyl ligands. Nature 431:830-834.

Paulais M, Lachheb S, Teulon J (2006) $\mathrm{A} \mathrm{Na}^{+}$- and $\mathrm{Cl}^{-}$-activated $\mathrm{K}^{+}$channel in the thick ascending limb of mouse kidney. J Gen Physiol 127:205-215.

Pegan S, Arrabit C, Zhou W, Kwiatkowski W, Collins A, Slesinger PA, Choe S (2005) Cytoplasmic domain structures of Kir2.1 and Kir3.1 show sites for modulating gating and rectification. Nat Neurosci 8:279-287.

Rosenhouse-Dantsker A, Logothetis DE (2006) New roles for a key glycine and its neighboring residue in potassium channel gating. Biophys $\mathrm{J}$ 91:2860-2873.

Rosenhouse-Dantsker A, Sui JL, Zhao Q, Rusinova R, Rodríguez-Menchaca AA, Zhang Z, Logothetis DE (2008) A sodium-mediated structural switch that controls the sensitivity of Kir channels to PtdIns(4,5)P(2). Nat Chem Biol 4:624-631.

Salkoff L, Butler A, Ferreira G, Santi C, Wei A (2006) High-conductance potassium channels of the SLO family. Nat Rev Neurosci 7:921-931.

Souaille M, Roux B (2001) Extension to the weighted histogram analysis method: combining umbrella sampling with free energy calculations. Comput Phys Commun 135:40-57.

Sui JL, Chan KW, Logothetis DE (1996) $\mathrm{Na}^{+}$activation of the muscarinic $\mathrm{K}^{+}$channel by a G-protein-independent mechanism. J Gen Physiol 108:381-391.

Tamsett TJ, Picchione KE, Bhattacharjee A (2009) NAD+ activates KNa channels in dorsal root ganglion neurons. J Neurosci 29:5127-5134.

Xia XM, Zeng X, Lingle CJ (2002) Multiple regulatory sites in largeconductance calcium-activated potassium channels. Nature 418:880884 .

Yang B, Desai R, Kaczmarek LK (2007) Slack and Slick K(Na) channels regulate the accuracy of timing of auditory neurons. J Neurosci 27:2617-2627.

Yuan A, Santi CM, Wei A, Wang ZW, Pollak K, Nonet M, Kaczmarek L, Crowder CM, Salkoff L (2003) The sodium-activated potassium channel is encoded by a member of the Slo gene family. Neuron 37:765-773.

Zeng XH, Xia XM, Lingle CJ (2005) Divalent cation sensitivity of BK channel activation supports the existence of three distinct binding sites. J Gen Physiol 125:273-286.

Zhang H, He C, Yan X, Mirshahi T, Logothetis DE (1999) Activation of inwardly rectifying $\mathrm{K}^{+}$channels by distinct PtdIns $(4,5) \mathrm{P} 2$ interactions. Nat Cell Biol 1:183-188. 